\title{
Yo-aquí-ahora: del texto escrito al audiovisual
}

\author{
Fanny Carolina Ortíz Pulido ${ }^{1}$ \\ Universidad Pedagógica y Tecnológica de Colombia
}

\section{Resumen}

En las sociedades modernas la palabra ha cedido terreno a la imagen gracias al auge de las nuevas tecnologías que han multiplicado la difusión icónica hasta el punto de alcanzar todos los campos de la vida. El lector requiere, por lo tanto, educar la mirada para acceder a la interpretación de un tipo de texto como el audiovisual. En consecuencia, y puesto que el lenguaje no se da sin deícticos, el propósito del siguiente estudio es analizar cómo esta categoría gramatical se manifiesta en los códigos icónicos y sonoros del cortometraje No todos los ríos van al mar (2008), del director colombiano Santiago Trujillo.

Palabras clave: texto, deixis, enunciación, código, icónico.

\begin{abstract}
At modern societies, the word has lost ground to the image by rise of new technologies that have multiplied iconic diffusion, affecting all areas life. The reader needs, therefore, educate your vision to interpret other type text, like audiovisual. Accordingly, and since the deictic are always present in language, The purpose this paper is analyze deictics like grammatical category and their demonstrations in iconic and sound code of short film No todos los ríos van al mar (2008), directed by Colombian Santiago Trujillo
\end{abstract}

Key words: text, deictic, enunciation, code, iconic.

\footnotetext{
${ }^{1}$ Especialista en Pedagogía del Lenguaje Audiovisual y Magíster en Lingüística de la Universidad Pedagógica y Tecnológica de Colombia. e-mail: fczitro@gmail.com
} Recibido: Marzo, 2010 - Aprobado: Junio, 2010. 
La fuerte presencia de la imagen se ha impuesto prácticamente en todos los espacios cotidianos: en el ocio, en la cultura, en la lúdica, y por supuesto, en la escuela. Esto se explica por el avance de la tecnología que ha propiciado el desarrollo de los lenguajes multimedia, es decir, aquellos que se transmiten por medios tan diversos como la televisión, el cine, la Internet, los teléfonos celulares y los impresos, implicando la existencia de diversos tipos de textos para leer. El lector actual necesita educar la mirada para acceder a la interpretación de otros lenguajes, puesto que toda práctica de la lectura y la escritura que no sea significativa para el niño se convierte en una tarea estéril. Debe propiciarse, por lo tanto, la expresión argumentada y crítica de las propias vivencias de los niños a través de la palabra escrita, pero también de la imagen y del audiovisual.

Lo anterior deja entrever la necesidad de abordar de manera razonada la lectura de textos elaborados mediante otros sistemas de significación como códigos icónicos (fotografía, escultura y pintura) y códigos sonoros (la música, v.gr.), pues una de las mayores dificultades para un lector no avezado se presenta al tratar de reconstruir el significado del texto: no llega a interpretar totalmente un enunciado, precisamente porque no advierte la connotación de muchos de estos códigos. Hay que notar, por otra parte, que los programas de enseñanza de lenguaje en educación básica y media -en concordancia con el giro lingüístico- han dejado de lado los enfoques reduccionistas de corte estructural, para dar paso al desarrollo de las competencias comunicativas. Y como resultado de esta tendencia, el estudio de la gramática está en riesgo de quedar relegado a un segundo lugar, con profundas consecuencias negativas, teniendo en cuenta que la gramática es fundamental para el conocimiento y la práctica de la propia lengua.

En consecuencia, el siguiente trabajo pretende proyectarse como una propuesta dirigida a los docentes, y se plantea como una alternativa para conciliar la enseñanza de la gramática con la lingüística aplicada desde un enfoque pragmático y semiótico, cuyo fin último es educar la mirada a través de la interpretación de la deixis en el texto audiovisual.

\section{La deixis}

Como tema de estudio, la deixis constituye un campo bastante amplio y enriquecedor aplicado a diferentes campos del conocimiento como la psicología, la filosofía y la lingúistica, entre otras disciplinas. Desde la óptica de la psicología del desarrollo, la deixis es el punto de partida para la adquisición del lenguaje, ya que el niño antes de aprender a 
nombrar las cosas, las señala, mientras que para la filosofía el ser humano se reconoce como individuo por medio de la deixis: ésta le permite expresar su egocentrismo.

En el ámbito de la lingüística, la deixis es estudiada como una categoría gramatical, pero también como un recurso básico para el desarrollo de la comunicación, por medio del cual los interlocutores se ubican en el espacio y en el tiempo, estableciendo relaciones entre ellos y los objetos, al mismo tiempo que se identifican en los roles conversacionales. Para concretar dicho objeto, además, siempre se acompaña de una mostración corporal (una mirada, un brazo extendido y un dedo que señala, o simplemente el tono de la voz). En otras palabras, el lenguaje no se da sin deícticos. En este orden de ideas, la deixis hace parte tanto del lenguaje verbal como del lenguaje no verbal, y su estudio compete también a la semiótica.

La deíxis constituye un aspecto fundamental para el lenguaje: en cada evento comunicativo siempre hay un deíctico dispuesto no sólo para ubicar y orientar a los hablantes, sino para señalar el universo al que se esté refiriendo. Los términos deíxis (en griego, "indicar" o "mostrar") e índice (en latín, "dedo que señala") se originan en el hecho de que el hablante intenta identificar el referente mediante un gesto corporal -de esta acción de indicar con el dedo se pasa a un concepto más general que se aplica a cualquier expresión referencial con propiedades deícticas-. En realidad, los deícticos son muy pocos, pero se adaptan fácilmente a cualquier situación: son tan útiles como oportunos.

En términos generales, podemos decir que los deícticos son unidades gramaticales de la lengua cuya función es señalar o indicar a los participantes, el momento o el lugar de la comunicación. Se distinguen varias clases de deícticos, realizados por diferentes categorías gramaticales:

- deíxis de persona: expresada mediante pronombres personales y posesivos y con morfemas verbales.

- deíxis temporal: realizada mediante los adverbios, locuciones y morfemas de tiempo.

- deíxis espacial: evidenciada mediante adverbios, demostrativos y verbos de significado locativo.

Además de las anteriores, Fillmore (1997) identifica dos nuevas categorías de deícticos de acuerdo con la naturaleza del referente: 
- Los deícticos del discurso, hacen referencia a aquellos apartes del discurso mismo que remiten a fragmentos del texto que se han dicho, (anafóricos), o que se van a decir, (catafóricos) y que de hecho están presentes en el entorno comunicativo y por lo tanto son susceptibles de ser señalados.

- Deícticos sociales, establecen la relación social entre los participantes que determinan la utilización de expresiones honoríficas, de respeto o de insulto. Este tipo de deíxis corresponde al campo de la pragmática.

De acuerdo con Bühler (1979), es posible que la mostración o deíxis se presente de tres modos diferentes:

- mostración ad oculos: consiste en mostrar o indicar algo que esté en el campo perceptivo de los interlocutores (alguien que hace referencia con el pronombre yo, siendo perceptible para el otro). Para que sea mostración ad oculos necesariamente se involucra al espacio físico donde se realiza el evento comunicativo del que se habla y se requiere de cualquier medio pre-lingüístico (el oído, un gesto, una mirada, un dedo que señala) para cumplir su función semántica.

- Sin embargo, también es posible una mostración en fantasma, o en ausencia del referente. Esto sólo se logra a través del lenguaje cuando se reconstruye un campo perceptivo imaginario al que remiten los deícticos, mediante un proceso de transposición, es decir, llevando la situación perceptiva ad oculos al plano del discurso (por ejemplo, un relato).

Según Bühler:

El hablante y el oyente de una relación intuitiva de cosas ausentes poseen los dones y recursos que permiten al actor en la escena hacer presente lo ausente y al espectador de la comedia interpretar lo presente en la escena como una mímesis de lo ausente (1979: 144).

La deíxis en fantasma involucra el conocimiento del mundo y se construye a través del recuerdo y la fantasía.

- Por último, la deíxis anafórica. Se da en el campo mostrativo contextual y es un mecanismo por el cual se retoma lo que ya se ha dicho mediante un recurso léxico gramatical que permita la identificación de un referente ya mencionado en el discurso: 
"con éste y aquél (o aquí y allí, etc.) se remite a lo recién tratado en el discurso, con el que (aquel que) se anticipa lo que va a tratar enseguida" (1979: 139). Los mismos mostrativos se utilizan anafóricamente aún cuando lo dicho prescinda de la situación.

De otra parte, a partir del trabajo de Bühler se determinan las "coordenadas" de todo acto de habla o de escritura, puesto que los deícticos realizan plenamente su significación en la medida en que estén ligados a la situación actual de comunicación. En otras palabras: siempre que hay un discurso, existe alguien que habla, un lugar desde donde se habla y un momento en el que se habla. Para Bühler estos tres elementos determinan el origen de todo acto de habla y se localizan a partir de tres palabras que tienen un carácter indexical: yo, aquí y ahora. Pero estas sólo adquieren valor en el momento en que son emitidas, puesto que desligadas de un contexto comunicativo carecen de significado. Este origen enunciativo permite organizar otro tipo de palabras y expresiones, por ejemplo temporales, como ayer o mañana, el otro día, que sirven para marcar una distancia temporal respecto al momento en que se pronuncian.

Según Lyons:

Por deixis se entiende la localización e iden-tificación de personas, objetos, eventos, procesos y actividades de las que se habla, o a las que se alude, en relación con el contexto espacio-temporal creado y sostenido por la enunciación y por la típica participación en ella de un solo hablante y al menos un destinatario (1980: 574).

De acuerdo con esta definición, para que el referente deíctico sea comprendido con exactitud es necesario conocer el contexto extralingüístico en el cual es utilizado. Por ejemplo, aquí designa un lugar que está cerca del hablante, y mañana, el día posterior a aquel en que se está hablando. En este sentido, es pertinente traer a colación el ejemplo de la nota que se encuentra en el pasillo: vuelvo enseguida. Aunque el significado es claro, el mensaje sólo podrá ser comprendido por alguien que sepa quién y cuándo fijó la nota. Esto quiere decir que, a pesar de que el significado de cada deíctico es único, el referente es variable y se fija cada vez que cambian el hablante, el oyente o las coordenadas espacio-temporales. Así, por ejemplo, la oración: allí estaré a la hora señalada varía con cada acto de enunciación, dependiendo de quién emita el enunciado y de cuándo y dónde lo haga. 
Desde otro punto de vista, puesto que todas las referencias a la estructura espacio-temporal hacen parte del campo mostrativo, la deíxis no se refiere únicamente al lenguaje verbal (oral o escrito). La imagen y el sonido también pueden ser interpretados como deícticos, en un lugar y en un tiempo precisos. Si bien las dimensiones del campo mostrativo son muy claras en lo lingüístico, en el texto fílmico como tal la configuración de la deixis es algo compleja. En el filme la deixis, en efecto, no se refiere únicamente al lenguaje verbal (oral o escrito), pues ésta también se logra a través de recursos técnicos, sonoros y visuales, dando lugar a la deixis audiovisual.

Llegado a este punto es necesario aclarar que tal término no existe, y sólo algunos teóricos del texto informativo, como es el caso de Vilches (1997), utilizan la expresión deixis icónica para explicar que ésta puede ser estudiada a nivel de la imagen. De acuerdo con el mencionado autor, "la deixis no es más que un modo particular de actualización de ciertas competencias que poseen los sujetos de la comunicación verbal-visual" (1997: 199). De manera que si este punto de vista es válido para el texto visual, de igual forma lo es para el audiovisual.

Empecemos por señalar que las deixis de persona y de lugar se infieren a partir de los mismos códigos. Al identificar la presencia del narrador se intuye el lugar en el que éste se ha instalado, de manera que lo que el espectador ve o escucha es lo que el narrador le transmite desde su campo perceptivo: "el enunciador y el enunciatario se sitúan dentro de coordenadas temporales y espaciales que impone el texto audiovisual y, desde esta mirada relativa, las expresiones deícticas no varían" (Pericot, 2002: 98). Jost, citado por Vilches, (1997) sostiene, además, que en la subjetividad de la imagen se puede interpretar la deixis: así, por ejemplo, el temblor de la cámara pone en evidencia la presencia física del narrador en la escena en el mismo momento en el que se desarrolla la acción, configurando totalmente las coordenadas del discurso fílmico.

De otra parte, el subrayado del primer plano, la sombra del personaje y el descenso del punto de vista por debajo del nivel de los ojos (angulación en picado), denotan un punto desde el cual se filma -aquí-, y por tanto, la cercanía o lejanía del objeto filmado (ahí, allí, allá). Igualmente, las imágenes marcadas con cierta deformación en relación con lo que se considera como una visión normal (por ejemplo, el desdoblamiento o la exageración del flou) remiten a un personaje ebrio, miope o delirante, y la mirada a la cámara cuando el personaje interpela al espectador son recursos a través de los cuales se manifiesta el personaje en primera persona. 


\section{El texto audiovisual}

Los autores de la Escuela de Tartu conciben el texto como acto de comunicación en general, sin restricción al campo lingüístico. Por esto Lotman ubica dentro de tal concepto a "cualquier comunicación que se haya registrado (dado) en un determinado sistema sígnico [...] en la misma medida en la que aplicamos este término a un texto escrito en una lengua natural, a un poema o a un cuadro" (1979: 41). El cine, por supuesto, se incluye dentro de los sistemas sígnicos a que se refiere Lotman: toda obra cinematográfica es un texto y como tal se abordará su estudio.

Definir la naturaleza del cine desde la óptica de la lingüística fue un tema recurrente en el siglo XX. Los estudios al respecto buscaban establecer aquellos rasgos característicos del cine que fueran equiparables a los de las lenguas naturales. Gracias a los aportes del francés Christian Metz se concluyó que el cine se inscribe dentro de los cánones de la pragmática, pues emplea un lenguaje de naturaleza sincrética en el que la imagen, el sonido y las palabras se entretejen para construir el texto fílmico:

La definida amplitud de su tejido depende de dos causas distintas cuyos efectos se superponen: por una parte, el cine engloba en sí un código -la lengua, en las películas "habladas" - cuya única presencia sería suficiente para autorizar las informaciones semánticas más variadas; en segundo lugar, los otros elementos del texto fílmico, por ejemplo las imágenes, ellas mismas son lenguajes cuya materia de contenido no tiene límites precisos (Metz, 1976: 160).

A los "otros elementos del texto fílmico", Metz los discrimina en códigos cinematográficos propios del cine (son el producto, a la vez, de la invención del cinematógrafo, que permite rodar planos, y del montaje de diversos planos con el fin de hacer una unidad, una película), y en códigos fílmicos no propios del cine (prestados de otras expresiones artísticas, aunque dotados de un rol específico dentro del filme), considerados como realidad cinematográfica sólo en cuanto están presentes en alguna película.

En este punto es necesario aclarar que, puesto que el tópico central en este trabajo es la deíxis no verbal, en adelante se tomará el término de audiovisual para hacer referencia a la imagen en movimiento, cuyo lenguaje es el cinematográfico, independientemente del tipo 
de soporte que se utilice, por lo cual la deíxis se leerá tanto en los códigos cinematográficos como en los códigos fílmicos.

El audiovisual es, pues, un texto de naturaleza sincrética, cuyos códigos guardan una relación coherente entre sí, con la intención de expresar, significar y comunicar; y su interpretación requiere de la competencia comunicativa del destinatario. Estos códigos estructurados tienen valores recurrentes, por lo que de ellos se pueden hacer referencias comunes, estableciendo una suerte de alfabeto con el que se escribe dicho texto.

\section{El acto comunicativo audiovisual}

De acuerdo con Bettetini, un "texto se manifiesta como el programa semiótico de una comunicación que se actualiza en la circunstancia concreta en la que el circuito comunicativo se clausura y el texto mismo queda consumado" (1986: 80). La razón de ser de cualquier texto, incluido el audiovisual, es la comunicación -entendida como la transferencia de un individuo a otro, implicando tanto una transmisión como una participación-. En efecto, el texto audiovisual es producto de la imaginación creativa de un autor concreto (un equipo humano detrás de cámaras que, por lo general, se condensa en la figura del director), cuyo destino es la lectura por parte de un potencial lector concreto.

Así pues, el texto es el objeto que se transmite y en torno al cual se interactúa. El propio texto delinea y condiciona la comunicación, pero no participa en ella, pues el verdadero factor en juego son los participantes con su comportamiento concreto. Como en todo proceso de comunicación, el emisor usa una serie de signos con el ánimo de ser entendido, y en virtud de esa intencionalidad, se ve obligado a utilizar signos convencionalmente aceptados y conocidos por el receptor, o bien, a dar las claves necesarias para entender las formas que proponga como signos.

En el caso del texto audiovisual, la actividad de los dos sujetos que intervienen en la comunicación está bien diferenciada: el emisor es siempre autor y el receptor siempre es el espectador, sin que se produzca alternancia de roles. Entre otras razones, debido a que no se cuenta con la presencia simultánea del destinador y el destinatario, y esta clase de texto, en consencuencia, tiene la necesidad de aclarar, mediante indicaciones precisas, el tipo de comunicación en el cual puede inscribirse de acuerdo con varias circunstancias: el tipo de destinador del que proviene, la clase de destinatario al que se dirige, cuál es su propósito y de qué modo se presenta. El texto 
audiovisual, desde este punto de vista, es un lugar de representación y de principios reguladores del acto comunicativo, evidenciado en la manera cómo las imágenes y los sonidos se disponen y operan.

\section{Enunciación y narración cinematográfica}

Si bien es cierto que un texto fílmico no implica posibilidad alguna de conversación paritaria entre un emisor y un receptor, en el sentido de conversación como tal, sí proyecta el desarrollo de una acción de acercamiento al espectador, conteniendo elementos concretos que guían la comunicación. De este modo, el texto audiovisual está constituido de tal forma que el receptor se pueda integrar a sí mismo en el mundo previsto para él. En palabras de Bettetini, "se podría decir que (el espectador) actúa con el fin de que el texto 'se integre' en su disponibilidad receptiva y por tanto 'converse' con él. Es una conversación fruto de una relación interactiva entre un texto y un sujeto receptor" (1986: 109).

Pues, aunque el audiovisual esté destinado a una comunicación unidireccional, el destinatario no desarrolla con el texto una relación comunicativa únicamente pasiva. El espectador no se limita a recibir el saber que el texto le comunica, sino que interactúa, a partir de la enunciación, con las situaciones que éste le propone. En una película lo que aparece representado es un mundo posible, y como tal, puede ser un "reflejo fiel" de la realidad, en cuyo caso se trata de un texto objetivo fácil de interpretar, o por el contrario, puede ser una visión particular del mundo, alejada de la realidad.

\section{No todos los ríos van al mar (2008), de Santiago Trujillo}

Si se tiene en cuenta que esta propuesta pedagógica pretende responder a unas expectativas didácticas precisas en vista de la necesidad de integrar el estudio de la gramática a la lingüística aplicada, a la pragmática y a la semiótica (para acceder a una lectura total del audiovisual), la metodología que adoptamos tiene como punto de partida el análisis textual para llegar a la hermenéutica. El paso preliminar consistió en fijar unos criterios claros para la selección del corpus: el primero de ellos, que no se tratara de cine comercial, debido a que éste maneja una serie de estereotipos que podrían interferir en la construcción del significado del filme. En segundo lugar, por manejo del tiempo, se prefirió que fuera un cortometraje, puesto que el análisis requería pausar la marcha de la proyección con el fin de observar detalladamente cuadro a cuadro. Por último, debía ser una producción colombiana, destacando el buen nivel alcanzado por nuestro cine. Por lo tanto, se optó por la 
lectura del cortometraje No todos los ríos van al mar (2008), del director Santiago Trujillo.

Una vez seleccionada la cinta, hicimos un primer acercamiento al filme en forma desprevenida, no sólo con la intención de conocer la historia, sino básicamente para preservar el goce que implica ver cine (el propósito es fomentar la cultura del cine, no tornarlo en una odiosa tarea escolar). Así obtuvimos una primera versión del contenido del relato, del cual quedó la "sensación" de que había escenas cuyo contenido parecía no tener relevancia en la historia. Luego de un segundo visionado, procedimos a identificar las secuencias narrativas, y en cada una de ellas, las secuencias fílmicas. Realizamos, posteriormente, el deletreo pormenorizado escena por escena, con el fin de captar cómo fueron dispuestos los diferentes códigos y las connotaciones, en términos de deixis y de instancias enunciativas, que estos pudieran tener en el planteamiento del relato.

Paso a paso, fuimos reconstruyendo simultaneamente el sentido del texto, hasta obtener una segunda versión y comprender el por qué de las escenas que parecían intrascendentes. Más tarde realizamos un nuevo visionado, sin pausas. De este modo pudimos verificar que en la interpretación inicial de la historia operaba un proceso de pensamiento formal bastante ajustado a la vida real, mientras que en la segunda se obtuvo una visión más amplia de la simbología de la imagen y de la manera como se puede llegar a construir mundos posibles. Por último, hicimos una revisión de la deixis lingüística en el guión literario para observar cómo operaba en este tipo de texto aspectos como el tiempo, el espacio y la modalidad.

No todos los ríos van al mar cuenta el drama de los niños de la guerra. La historia se basa en una experiencia real de la fundación "Disparando cámaras para la paz", que promueve el intercambio de correspondencia entre niños refugiados de distintos lugares del mundo. El filme cuenta la historia de Yenny y Esmeralda, dos hermanas recién llegadas a un barrio de desplazados en Bogotá. Yenny, la menor, no puede ir al colegio y tiene que dedicarse a las tareas del hogar. Su vida cobra sentido cuando, a través de cartas, se hace amiga de Hassan, un niño afgano desplazado por la guerra, al tiempo que conoce a Jairo, un muchacho solitario que, a pesar de su corta edad, sabe demasiado de la vida y de la muerte. Las cartas, repentinamente, dejan de llegar y Esmeralda, conmovida por la tristeza de su hermana, se decide a suplantar a Hassan. Yenny, al tiempo que muere Jairo, descubre el engaño, pero (por fortuna) logra ingresar al colegio y recupera el ánimo para intentar que ahora sí el río llegue al mar. 
Una vez realizado el análisis textual pudimos determinar cómo se ha delineado la comunicación entre los participantes, de tal forma que la figura del destinador se identifica con Santiago Trujillo, el director, y con el Alto Comisionado de las Naciones Unidas para los Refugiados. Los dos se constituyen como un solo enunciador cuya intención es la de destacar los factores generadores de violencia en contra de la niñez, y lo hacen en forma indirecta con la historia que recrean, y en forma directa por medio de los protagonistas con sus cartas y fotografías. En consecuencia, el perfil del espectador implícito corresponde a cualquier persona que tenga en sus manos la capacidad de contribuir a la erradicación de este problema, entre ellas los gobernantes y los docentes: los primeros, porque pueden generar, desde políticas muy precisar, condiciones dignas de vida que, indudablemente, conllevan a la paz; y los segundos, porque, además de su enorme labor social, pueden contribuir a que los pequeños no pierdan la capacidad de soñar: sólo así mantendrán viva la fe en un mundo mejor y sabrán que si luchan por ello, lo harán realidad.

De modo que la interacción entre el destinatario y el texto se puede dar en la medida en que el relato logre sensibilizar al espectador, y para ello cuenta con dos recursos poderosos: 1) la banda sonora, cuya suave tonada transmite melancolía y desolación ante el futuro de la niñez en un mundo cada vez más violento, y 2 ) la imagen, intento de ser un "fiel reflejo" de la realidad de los desplazados, como se aprecia en una secuencia de fotogramas: ranchos improvisados, ausencia de servicios públicos, calles empinadas y descubiertas, con seres que llevan a cuestas cargas pesadas. Podemos encontrar, además, la situación de abandono de los niños, y los riesgos que conlleva esta condición: no cuentan con un sitio adecuado para jugar; en muchos casos representan una carga para sus padres y deben asumir roles propios de los adultos, y por lo general son víctimas de la violencia intrafamiliar (por lo que no es de extrañar que muchos de ellos sean actualmente protagonistas de hechos de violencia).

En lo que se refiere al sujeto de la enunciación, su presencia se advierte a través de un narrador omnisciente que mira a los personajes desde arriba (angulaciones en picado), denotando que se trata de un adulto que se acerca a los niños para mostrar la realidad de la que él mismo es testigo. En su mundo posible se atribuye el don de la ubicuidad, situándose simultáneamente en dos planos espaciotemporales diferentes. Así, por ejemplo, hay un momento en que la que las imágenes muestran las calles de barrio de los desplazados en Bogotá, mientras se escucha en primer plano la voz de Hassan y el sonido incidental producido por el barullo de los niños que juegan en la calle. En otras palabras, si se tiene en cuenta que el narrador nos 
transmite lo que ve y lo que oye, es de suponer que está al mismo tiempo en dos lugares diferentes: Colombia y Afganistán.

Otro aspecto en el que se evidencia el discurrir del narrador en el tiempo y en el espacio podemos encontrarlo en la secuencia número 8 del filme, donde se alternan imágenes entre pasado y presente -aquí y allá-: cuando el profesor le explica a Esmeralda que Hassan ha muerto, las imágenes y los sonidos no diegéticos recrean sutilmente la ansiedad de Yenny, la tristeza de Esmeralda (presente, aqui) y la agonía del niño (pasado, allá, el no lugar al que van los muertos). Es así como el enunciatario hace alarde de la versatilidad del cine, condensando en pocos minutos, y en unas cuantas imágenes, gran cantidad de información de la cual se sirve para delinear la trama.

En suma, las posibilidades expresivas del audiovisual ponen de manifiesto la triada lingüística Yo-Tú-Ellos. Es decir, yo (enunciador); aquí y ahora te cuento a ti (enunciatario); y la historia de ellos (los niños de las guerras que se libran aquí y allá). Al tener en cuenta esto se puede afirmar que a través de la deixis se llega fácilmente al estudio del texto, cualquiera que sea su naturaleza, puesto que permite identificar la voz del enunciador, así como la intención implícita en su discurso, favoreciendo la consecución de mejores resultados a nivel de interpretación de lectura, hasta llegar al nivel ideal: el diálogo entre el texto y su lector. Hay así, pues, suficientes elementos de juicio para afirmar que la lingüística puede y debe ocuparse de un terreno olvidado, como es el de la imagen, tal como lo sustentan las siguientes razones:

- Una imagen por sí sola no significa nada; su significado lo adquiere cuando el lector la interpreta y la dota de sentido. Esto lo hace mediante el lenguaje.

- Los mundos posibles que construye el cine, como los sueños, también están dentro del lenguaje.

- Debido a la naturaleza ecléctica del texto audiovisual, éste tiene la capacidad de sintetizar gran cantidad de información, por lo cual puede ser utilizado como una excelente ayuda pedagógica.

- Si se estudia bien la deixis lingüística se puede ayudar a los niños a comprender el mundo audiovisual en el que viven.

- Es necesario que los niños escriban desde su experiencia del mundo. De esta forma se pueden acortar las brechas que se han abierto entre el conocimiento y las vivencias de los niños 


\section{Bibliografía}

Alarcos Llorach, E. (1994). Estudios de gramática funcional del español. Madrid: Gredos.

Benveniste, E. (1993. Problemas de lingüística general. México. México: Siglo XXI. 2vol.

Bertorello, A. (2008). El límite del lenguaje: la filosofía de Heidegger como texto de la enunciación. Buenos aires: Biblos.

Betettini, G. (1986). La conversación audiovisual. Madrid: Cátedra.

Blanco, D. (2003). Semiótica del texto fílmico. Lima: Universidad de Lima. Fondo de desarrollo editorial.

Bordwell, D. y Thompson, K. (1995). El arte cinematográfico. Barcelona: Paidós.

Boves Naves, C. (1989). La semiología. Madrid: Síntesis.

Brown, G y Yule, G. (1993). Análisis del discurso. Madrid: Visor.

Bühler, K. (1979). Teoría del lenguaje. Madrid: Alianza Universidad.

Casetti, F. (1989). El Film y su espectador. Madrid: Cátedra.

(1994). Teorías del cine. Madrid: Cátedra.

Casetti, Francesco y Di Chio, F. (1998). Cómo analizar un filme. Barcelona: Paidós.

Courtes, J. (1980). Introducción a la semiótica discursiva. Buenos Aires: Hachette.

Deleuze, G. (1984). La imagen-movimiento. Estudios sobre cine 1. Barcelona: Paidós.

(1985). La imagen-tiempo. Estudios sobre cine 2. Barcelona: Paidós.

Dmytryk, E. (1995). El cine, concepto y práctica. México: Limusa.

Eco, U. (1999). Lector in fábula. Barcelona: Lumen.

(1986). La estructura ausente. Barcelona: Lumen.

Fillmore, C. (1997). Lectures on Deixis. Stanford: CSLI Publications.

García Jiménez, J. (1993). Narrativa audiovisual. Madrid: Cátedra.

Genette, G. (1988) Nuevo discurso del relato. Madrid: Cátedra.

Goyes Narváez, J. C. (2008). "Leer es escribir: la experiencia de la imaginación”, Educación y ciudad, n¹5, Alcaldía Mayor de Bogotá, Bogotá, pp. 47-60.

. (2002). "Horizontes de la comunicación visual contemporánea", Espéculo. Revista de estudios literarios, $\mathrm{n}^{\circ} 22$, Universidad Complutense de Madrid, en http://www.ucm.es/info/especulo/ numero22/com_visu.html

Greimas, A. J. y Courtes, J. (1982) Semiótica: diccionario razonado de la teoría del lenguaje. Madrid: Gredos.

Kerbrat-Orecchioni, C. (1986). La enunciación: de la subjetividad en el lenguaje. Buenos Aires: Hachette.

Konisberg, I. \& Herrando Pérez, E. (2004). Diccionario técnico Akal de Cine. Madrid: Ediciones Akal. Vol. III.

Lotman, Y. \& Lozano, J. (1979). Semiótica de la cultura. Madrid: Cátedra.

Lyons, J. (1981). Lenguaje, significado y contexto. Barcelona: Ediciones Paidós. 
Metz, C. (1973). Lenguaje y cine. Barcelona: Planeta.

Mitry, J. (1978). Estética y psicologías del cine I. Las estructuras. Madrid: Siglo XXI.

(1986). Estética y psicologías del cine II. Las formas. Madrid: Siglo XXI.

Pericot, J. (2002). Mostrar para decir: la imagen en contexto. Barcelona: Universidad Autónoma de Barcelona.

Seco, R. (1973). Manual de gramática española. Madrid: Aguilar.

Serrano, S. (1981) La Semiótica, una introducción a la teoría de los signos. Barcelona: Montesinos.

Varela, J. et al. (2004) Lengua y sociedad: lingüística aplicada en la era global y multicultural. Santiago de Compostela: Universidad Santiago de Compostela.

Van Dijk, T. (1988) Texto y contexto. Madrid: Cátedra.

Vilches, L. (1997) La lectura de la imagen, prensa, cine, televisión. Barcelona: Paidós.

Zunzunegui, S. (1995) Pensar la imagen. Madrid: Cátedra. 